\title{
Tear secretion and tear film stability in Nigerians with non-insulin dependent diabetes mellitus
}

\author{
FK Idu* and E Oghre
}

*Department of Optometry, Faculty of Life Sciences, University of Benin, P.M.B 1154, Benin City, Edo State, Nigeria.

<faustikem@yahoo.com>

Received 27 April 2010; revised version accepted 30 September 2010

\begin{abstract}
It has been reported that many diabetic patients complain of dry eye symptoms. Thus this study was aimed at investigating tear secretion and tear film stability in patients with non-insulin dependent diabetes mellitus (NIDDM). Eighty (80) subjects within the age range of 50-60 years with mean age of $55 \pm 3.42$ years were recruited for this study. They comprised of 40 NIDDM patients (19 males and 21 females) and 40 age and gender matched controls (18 males and 22 females) without diabetes. Schirmer test and invasive tear break up time (TBUT) were used to determine tear secretion and tear film stability respectively. Results showed an apparent reduction in both total and basal tear secretions for the NIDDM patients compared with that for control subjects. However this reduction was not statistically significant with the unpaired
\end{abstract}

$t$-test. $(p>0.05)$. Unpaired $t$-test revealed a statistically significant reduction in TBUT of the NIDDM group compared with control subjects. Correlation analysis revealed a negative correlation between fasting blood sugar (FBS) levels and both basal and total tear secretions. $(r=-0.51$, $p<0.05)$ and $(r=-0.54 p<0.05)$ respectively. There was also a negative correlation between FBS and TBUT ( $r=-0.34 p=0.03)$. The student $t$-test showed no influence of gender on both tear secretions and TBUT for NIDDM patients and controls. This study shows that both tear secretion and tear film stability are affected by NIDDM, and concurs with the findings that diabetic patients often complain of dry eye symptoms. ( $S$ Afr Optom 2010 69(3) 140-145)

Key words: Diabetes mellitus, dry eye, tear secretion, tear film stability

\section{Introduction}

Type 2 diabetes mellitus or non-insulin dependent diabetes mellitus (NIDDM) is a multi-factorial disease that may involve improper insulin secretion, malfunctioning insulin and or insulin resistance in peripheral tissues ${ }^{1,2}$. Researchers have documented various ocular manifestations of diabetes mellitus to include large fluctuations in refraction, premature cataractogenesis and non proliferative and proliferative retinopathy ${ }^{3}$. It has also been noted that many diabetic patients complain of dry eye symptoms such as burning or foreign body sensation, and dryness ${ }^{4}$. Keratoconjunctivitis sicca has been reported to be more common amongst diabetic patients ${ }^{5}$. Complications like alterations in functions of the autonomic nervous system with associated signs of changes in pupillary size and abnormal reaction of pupil to light have been reported ${ }^{6,7}$. Murat et $a l^{8}$ reported significantly lower tear break up time (TBUT) and Schirmer test values in diabetic patients 
compared with non-diabetic subjects. However, there have been many controversial reports about changes in tear film parameters in diabetics $9,10,11$.

Although several studies have documented tear secretion and tear film function in non insulin dependent diabetes mellitus, there have been few studies from Nigeria.

\section{Materials and methods}

\section{Subjects}

Eighty (80) subjects within the age range of 50-60 years comprising 37 males and 43 females were used for this study. The subjects included 40 (19 males and 21 females) non-insulin dependent diabetic patients and 40 (18 males and 22 females) non-diabetic subjects who served as controls. All subjects were Nigerians living in the Edo and Delta states of the country. The NIDDM patients who formed the experimental group were volunteers from the Medical Outpatient Department (MOPD) of the Central Hospital Benin City, Edo state, Nigeria. Controls were randomly selected from the general population to match age and gender of the experimental group. All experiments were carried out in the eye clinic of the Central Hospital, Benin City.

Informed consent was obtained from each of the participants and the study was approved by the Ethics Committee of Central Hospital, and was performed in accordance with the guidelines of the Declaration of Helsinki.

\section{Inclusion criteria}

- $\quad$ All diabetic patients had just been diagnosed with NIDDM and had not started any medication. They had fasting blood sugar of $7.7 \mathrm{mmol} / \mathrm{L}$ and above.

- Non-diabetic controls had normal values of fasting blood glucose levels of $5.6 \mathrm{mmol} / \mathrm{L}$ and less, and negative personal and family histories of diabetes mellitus.

\section{Exclusion criteria}

- Subjects were excluded due to history of previous ocular surgery and laser treatment, recent use of topical eye drops, use of contact lenses, pregnancy, history of systemic diseases with ocular manifesta- tions affecting tear secretion, infectious keratoconjunctivitis and any other ocular surface condition that may affect tear secretion or distribution.

\section{Description of procedure}

Case histories which involved a concise ophthalmic and systemic history of each subject were conducted. Preliminary eye examination using a penlight to examine the external ocular and anterior segment structures and fundoscopy using the direct opthalmoscope were carried out. Subjects who met the selection criteria were then recruited for the study.

\section{Schirmer Test}

Schirmer test was carried out with and without local anaesthetic agent to measure both basal and total tear secretions respectively. Each subject was asked to sit in an upright position in dim room illumination. The subject was asked to look up while a standard Schirmer tear test strip was gently inserted at the lateral one third of the lower lid of the right eye (OD) without touching the cornea. After five minutes the strip was gently removed and the level of wetting was measured in millimeters. The value gave the total tear secretion rate. After 10 minutes of rest, one drop of $0.5 \%$ tetracaine was instilled into the lower conjunctival fornix of the left eye (OS) and the above procedure repeated. This value gave the basal tear secretion rate. Length of wetting of less than $10 \mathrm{~mm}$ in five minutes was considered low tear secretion for both procedures.

\section{Tear Break Up Time (TBUT)}

The end of a fluorescein strip was moistened with one drop of distilled water and applied to the subject's temporal bulbar conjunctiva. The subject was asked to blink several times to spread the dye over the corneal and conjunctival surfaces and then asked to keep the eyes open looking straight ahead. The Burton lamp with the cobalt blue filter was used to scan the entire cornea looking for dry areas which appeared as dark spots or streaks. The time in seconds between the last blink and the first appearance of a dry spot was recorded with a stopwatch as the TBUT. The mean of three consecutive TBUT was taken. A TBUT of less than 10 seconds was indicative of an unstable tear firm. 


\section{Statistical analysis}

All the compiled data was analyzed with STATGRAPHICS plus 5.1. Unpaired $t$-tests were employed to compare data between diabetic and control groups. Correlation analysis was used to test for correlation between fasting blood sugar (FBS) and tear secretions, and FBS and TBUT of both the experimental group. Unpaired $t$-tests were used to compare the data of tear secretion and TBUT between males and females of the experimental group. Significance was declared when probabilities values, $p<0.05$.

\section{Results}

The mean basal tear secretion in mm per five minutes for both non insulin dependent diabetic subjects and controls were $10.53 \pm 7.9 \mathrm{~mm}$ per five minutes and $11.06 \pm 5.3 \mathrm{~mm}$ per five minutes respectively. The value in the NIDDM showed a slightly lower secretion than the control, but unpaired $t$-test showed no significant difference in both groups, $(p>0.05)$.

The mean total tear secretion in $\mathrm{mm}$ per five minutes for both NIDDM and control groups were 12.20 $\pm 8.1 \mathrm{~mm}$ per five minutes and $13.36 \pm 7.2 \mathrm{~mm}$ per five minutes respectively. There was a slightly lower mean total tear secretion amongst the NIDDM group but this was not statistically significantly different from the control group with the unpaired $t$-test $(p>0.05)$

The mean TBUT in seconds for NIDDM and control groups were $8.99 \pm 3.3$ seconds and $13.70 \pm 3.5$ seconds respectively. Unpaired $t$-test revealed a significantly lower mean TBUT amongst NIDDM patients. $(p=0.03)$

Table 1 shows mean basal tear secretion and mean reflex tear secretion for males and females in both NIDDM and controls groups. The student $t$-test showed no significant difference in both basal and reflex tear secretions between the male and female subjects in both groups.

Table 1: Mean basal tear secretion and mean reflex tear secretion for males and females in both NIDDM and controls groups
Table 2: Mean TBUT for males and females in both NIDDM and control groups and mean FBS for both males and females in the NIDDM group.

\begin{tabular}{|c|c|c|c|c|c|c|}
\hline SEX & $\mathrm{n}$ & $\begin{array}{c}\text { NIDDM } \\
\text { Mean } \\
\text { TBUT in } \\
\text { secs }\end{array}$ & $\begin{array}{c}\text { NIDDM } \\
\text { Mean FBS } \\
\text { in mmol/L }\end{array}$ & $\mathrm{n}$ & $\begin{array}{c}\text { CONTROL } \\
\text { Mean } \\
\text { TBUT in } \\
\text { secs }\end{array}$ & $\begin{array}{c}\text { CONTROL } \\
\text { Mean FBS } \\
\text { in mmol/L }\end{array}$ \\
\hline male & 15 & $9.50 \pm 3.8$ & $\begin{array}{c}11.69 \pm \\
4.7\end{array}$ & 14 & $14.37 \pm 4.2$ & $4.65 \pm 0.6$ \\
\hline female & 17 & $8.4 \pm 3.4$ & $\begin{array}{c}13.03 \pm \\
6.9\end{array}$ & 18 & $13.03 \pm 2.7$ & $4.53 \pm 0.6$ \\
\hline
\end{tabular}

Table 2 shows the mean TBUT and mean fasting blood sugar (FBS) for males and females in both NIDDM group and control group. Student $t$-test showed no significant difference in TBUT and FBS between males and females in the NIDDM group and between males and females in the control group. However there was a significant difference in TBUT and FBS between males in the NIDDM group and those of the control group. Same goes for the females in both groups. Mean FBS was higher in female NIDDM group than in male NIDDM group, but was lower in female than in male control groups.

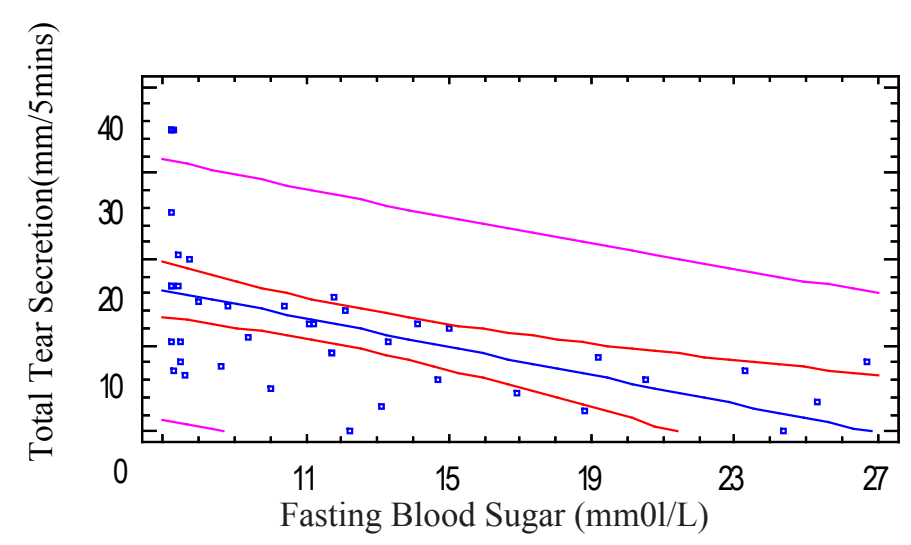

Figure 1: Relationship between fasting blood sugar and total tear secretion in the NIDDM group. (TTS = Total tear secretion, BTS $=$ Basal tear secretion)

\begin{tabular}{|l|c|c|c|c|c|c|}
\hline SEX & $\mathrm{n}$ & $\begin{array}{c}\text { NIDDM } \\
\text { Mean } \\
\text { basal tear } \\
\text { secretion in } \\
\mathrm{mm} / 5 \mathrm{~min}\end{array}$ & $\begin{array}{c}\text { NIDDM } \\
\text { Mean } \\
\text { total tear } \\
\text { secretion in } \\
\mathrm{mm} / 5 \mathrm{mins}\end{array}$ & $\mathrm{n}$ & $\begin{array}{c}\text { CONTROL } \\
\text { Mean } \\
\text { basal tear } \\
\text { secretion in } \\
\mathrm{mm} / 5 \mathrm{mins}\end{array}$ & $\begin{array}{c}\text { CONTROL } \\
\text { Mean } \\
\text { total tear } \\
\text { secretion in } \\
\mathrm{mm} / 5 \mathrm{mins}\end{array}$ \\
\hline male & 19 & $11.69 \pm 8.9$ & $13.04 \pm 8.8$ & 18 & $12.95 \pm 7.7$ & $14.34 \pm 8.3$ \\
\hline female & 21 & $9.26 \pm 6.7$ & $11.30 \pm 5.2$ & 22 & $9.18 \pm 3.7$ & $10.79 \pm 7.1$ \\
\hline
\end{tabular}




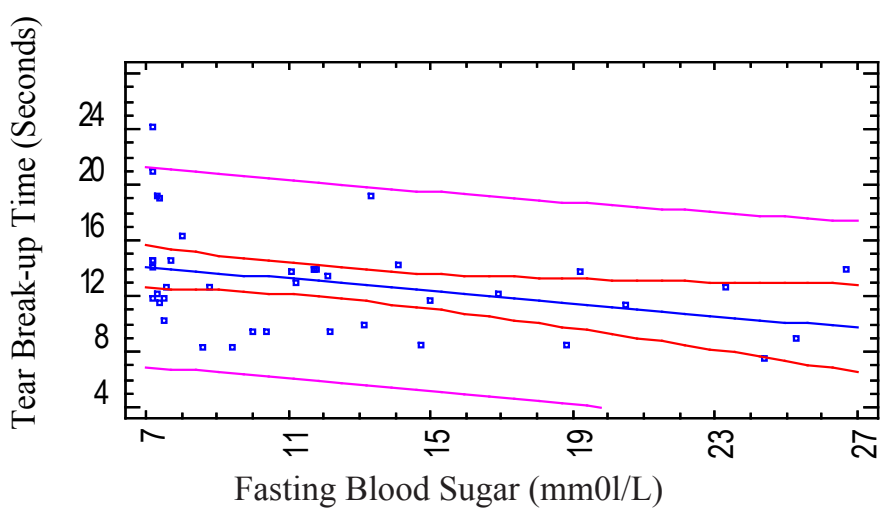

Figure 2: Relationship between fasting blood sugar and basal tear secretion in the NIDDM group.

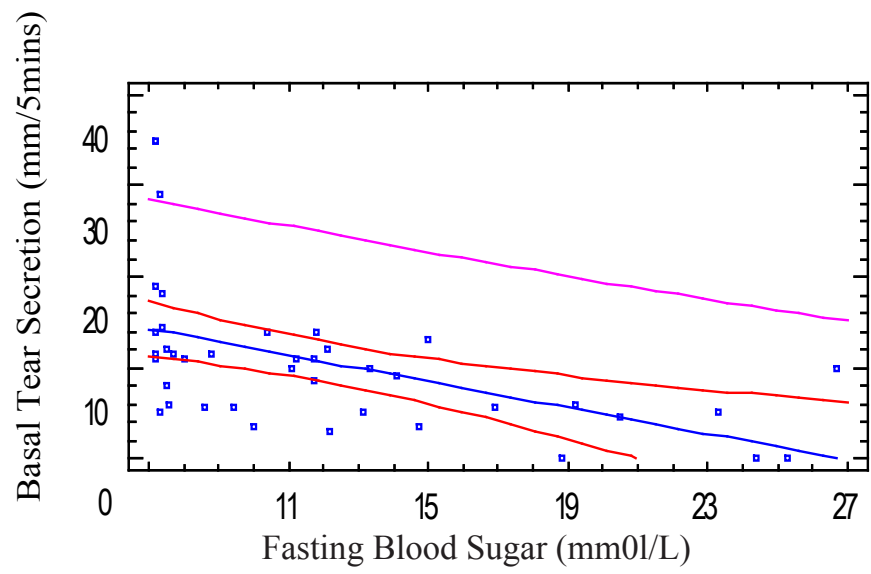

Figure 3: Relationship between fasting blood sugar and Tear Break Up Time (TBUT) in NIDDM group.

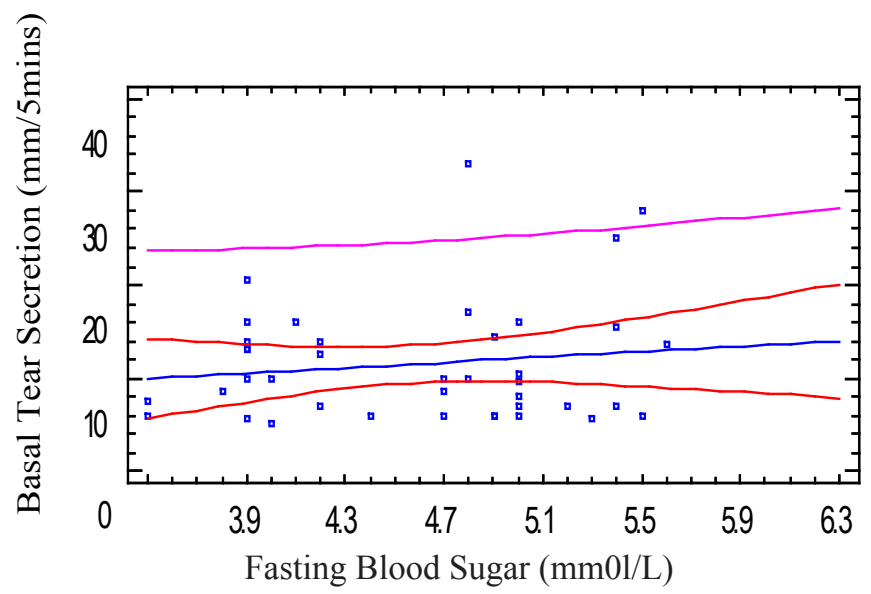

Figure 4: Relationship between fasting blood sugar and total tear secretion in the control group.

Figures 1, 2 and 3 show the relationship between fasting blood sugar and total tear secretion, basal tear secretion and TBUT respectively in the NIDDM group. Correlation analysis shows a statistically significant negative correlation between these parameters. FBS and total tear secretion $(r=-0.54, p<0.05)$,
FBS and basal tear secretion $(r=-0.51, p<0.05)$, FBS and TBUT $(r=-0.34, p=0.03)$.
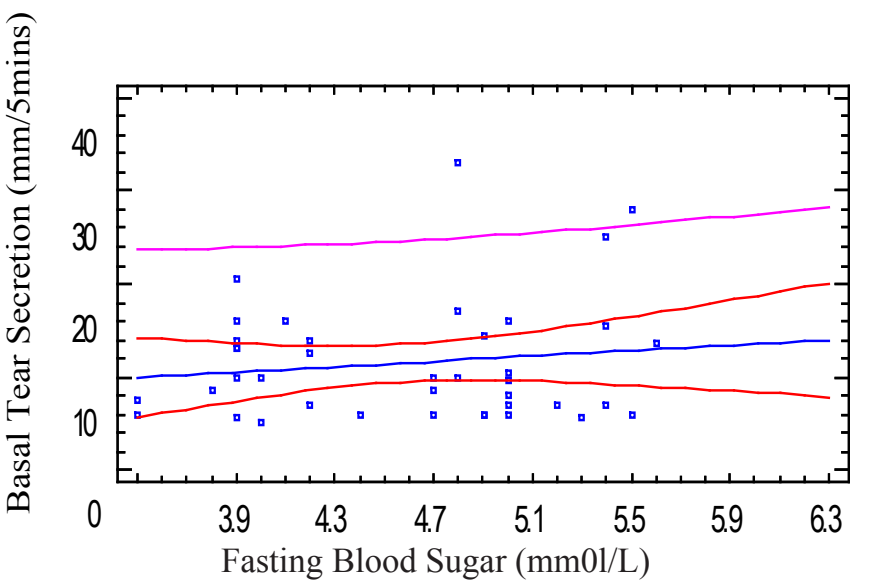

Figure 5: Relationship between fasting blood sugar and basal tear secretion in the control group.

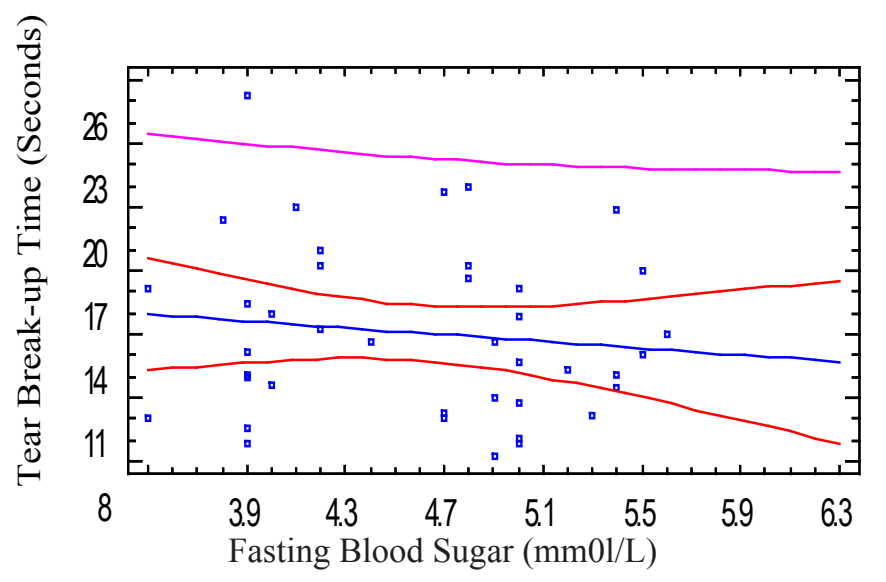

Figure 6: Relationship between fasting blood sugar and tear break up time in the control group.

Figures 4, 5 and 6 show the relationship between fasting blood sugar and total tear secretion, basal tear secretion and TBUT respectively in the control group. Spearman correlation analysis shows no statistically significant relationship between these parameters. FBS and total tear secretion $(r=-0.18, p=0.26)$, FBS and basal tear secretion $(r=0.14, p=0.40)$, FBS and TBUT $(r=-0.12, p=0.45)$.

\section{Discussion}

Basal tear secretion, total tear secretion and tear break up time (TBUT) in patients with non-insulin dependent diabetes mellitus were assessed in this study and results compared with those of normal subjects. The function of tears is to lubricate, nourish and protect the eye from dust and other irritants thus pre- 
venting infections. They also keep the surface of the eye optically clear and smooth. Imbalance in the composition of tears, decreased tear production or excessive tear evaporation can lead to tear film dysfunction collectively diagnosed as "dry eyes"12. It has been noted that many diabetic patients often complain of dry eye symptoms.

The Schirmer test measures the volume of tear produced within a five minute period. Schirmer test without topical anaesthesia measures the total tear secretion while that with topical anaesthesia eliminates the reflex tearing produced by irritation of the strip and this wetting of the strip represents the basal tear secretion $^{13}$. The invasive tear break up time (TBUT) measures the stability of the tear film ${ }^{14}$.

The results of this study showed an apparent reduction in both basal and reflex tear secretions for NIDDM patients compared with normal subjects. However, this reduction was not statistically significant. Previously published results ${ }^{11,15}$ have also reported reduced tear secretion in NIDDM patents. This has been attributed to alterations of the parasympathetic portion of the autonomic nervous system which supplies the lacrimal glands. Studies ${ }^{10,16}$ have reported marked parasympathetic alterations in diabetic patients which could probably lead to reduced nervous supply to the lacrimal glands and in turn reduced aqueous tear production. The reflex tear secretion that has to do with corneal irritation is highly dependent on the sensitivity of the cornea. It has been shown that diabetic patients present with corneal epithelial abnormalities compared to normal individuals and that these abnormalities reduce corneal sensitivity and in turn lead to reduced production of reflex tears ${ }^{17}$.

This study showed a statistically significant decreased tear breakup time (TBUT) in the NIDDM group as compared to normal subjects which showed that they had an unstable tear film compared to controls subjects. This finding is also consistent with results of some previous researches $10,11,15$. It has been previously reported 5,11 that diabetic patients suffer from squamous cell metaplasia and goblet cell loss. Goblet cells of the conjunctiva secrete the mucin portion of tears which contribute to tear film stability. Therefore goblet cell loss in diabetes will affect tear film stability.

The study also revealed a negative correlation between fasting blood sugar (FBS) and tear secretions,
FBS and TBUT using correlation analysis. This shows that the higher the FBS the lower the tear secretion and tear film stability.

It was also revealed from the study that gender had no influence on tear secretion and tear film stability in both the diabetic and control groups.

\section{Conclusion}

It is concluded that tear film stability is decreased in diabetic patients. More investigations are however recommended for tear production. These results suggest that diabetic patients are more prone to suffering from dry eye symptoms than normal subjects and therefore eye care practitioners are advised to watch out for these symptoms.

\section{Acknowledgment.}

We gratefully acknowledge the assistance of Dr Ephraim Maduaguna.

\section{References}

1. Wilson DJ. Diabetes Mellitus. In: Fauci A, Braunwald E, Iselbacher KJ, et al, ed. Harrison's Principles of Internet Medicine Companion Handbook, 14th ed. New York: MC Graw Hill, 1998 pp 943-946.

2. Crawford JM. Liver Biliary system and Pancreas. In: Robbins SL, Cotran RS, Kumar V. ed. Pocket Companion to Robbins Pathologic Basis of Disease, 5th ed. Philadelphia, PA: WB Saunders Co., 1995 pp 367-374.

3. Sowka JW, Gurwood AS, Kabat GA. Diabetes mellitus, handbook of ocular disease management. Available at http: www.revoptom.com/handbook/March 2004, Accessed July 2005.

4. Seifart U, Strempel I. The dry eye and diabetes mellitus. Ophthalmol 199419 23-29.

5. Kaiserman I, Kaiserman N, Nakar S, Vinker S. Dry eye in diabetic patients. Am J Ophthalmol 2005139 498-503.

6. Dogru M, Katakami C, Inoue M. Tear function and ocular surface changes in non insulin dependent diabetes mellitus. Ophthalmol 2001108 586-592.

7. Good KL, Maggs DJ, Hollingworth SR, Scaghotti RH, Nelson RW. Corneal sensitivity in dogs with diabetes mellitus. Am J Vet Res 200364 7-11.

8. Murat D. Tear function and ocular surface changes in non insulin dependent diabetes mellitus. Ophthalmol 2001108 586-592. 
9. Stolwijk TR, Van-Best JA, Lemkes HH,de Keizer RJ, Oosterhuis JA. Determination of basal tear turnover in insulin dependent diabetes mellitus patients by fluorophotometry. Int Ophthalmol 199115 377-382.

10. Goebbels M. Tear secretion and tear film function in insulin dependent diabetes. Br J Ophthalmol 200084 19-21.

11. Ling Y, Xiaoming C, Gang Q, Hanping X, Peng L. Tear film function in type 2 diabetic patients with retinopathy. Ophthalmologica 2008222 284-291.

12. Gupta PD. Pathophysiology of lacrimal gland in old age. $W$ J Med Sci 2006 1 1-8.

13. Carlson N, Kurtz D. Schirmer Tests. Clinical Procedures for Ocular Examination 3rd ed., Mc Graw-Hill, London 2004 pp 260.

14. Carlson N, Kurtz D. Tear Break up Time. Clinical Procedures for Ocular Examination 3rd ed., Mc Graw-Hill, London 2004 pp 258.

15. Jin J, Chen LH, Liu XL, Tear film function in non insulin dependent diabetics. Zhongua yank e Za Shi 200339 10-13

16. Ramos-Remus C, Suarez-Almazor M. Low tear production in patients with diabetes mellitus is not due to Sjogren's syndrome. Clin Exp Rheumatology 19944 375-380.

17. Saito J, Enoki M, Hara M, Morishige N, Chikama T, Nishida T. Correlation of corneal sensation but not of basal or reflex tear secretions with stages of diabetes retinopathy. Cornea 200322 15-18. 